\title{
A REVIEW ON ALUMINUM TOXICITY AND QUANTITATIVE TRAIT LOCI MAPPING IN RICE (ORYZA SATIVA L)
}

\author{
RASHEED, A. ${ }^{1}-$ FAHAD, S. ${ }^{2}-$ HASSAN, M. U. ${ }^{3}-$ TAHIR, M. M. ${ }^{4}-$ AAMER, M. ${ }^{3}-$ WU, Z. M. ${ }^{1 *}$ \\ ${ }^{1}$ Key Laboratory of Crop Physiology, Ecology and Genetic Breeding, Ministry of \\ Education/Collage of Agronomy, Jiangxi Agricultural University \\ Nanchang 330045, PR. China \\ ${ }^{2}$ Department of Agriculture, University of Swabi, Khyber Pakhtunkhwa, Pakistan \\ ${ }^{3}$ Research Center on Ecological Sciences, Jiangxi Agricultural University \\ Nanchang 330045, PR. China \\ ${ }^{4}$ Department of Soil and Environmental Sciences, Faculty of Agriculture, University of Poonch, \\ Rawalaot, Azad Jammu and Kashmir, Pakistan \\ *Corresponding author \\ e-mail:wuzm@jxau.edu.cn
}

(Received $1^{\text {st }}$ Dec 2019; accepted 24 $4^{\text {th }}$ Mar 2020)

\begin{abstract}
Rice is one of the main staple foods of 50\% of the world's population. Aluminum (Al) toxicity is affecting rice growth on acidic soils. We described positive and toxic effects of aluminum on rice, growth on acidic soils as well as function of mutant genes viz. Nrat1, ART1, STAR1 and STAR2 which require further analysis, especially regulation of ARTI, STARI at transcriptional level to unfold their role in $\mathrm{Al}$ tolerance. Nratl gene involved in natural variations for $\mathrm{Al}$ tolerance and this would be a novel step in generating natural variation in rice populations. This review highlighted strong theoretical base to understand Al toxicity tolerance mechanisms in rice and we presented several quantitative trait loci e.g. qRRE-11, qRRE-1 controlling Al tolerance in rice at seedling stage which could be transferred via master-assisted selection to enhance $\mathrm{Al}$ tolerance in rice. Preliminary screening technique using $\mathrm{Al}$ toxic levels is an ideal way to screen resistant seedling in hydroponic environment with the secondary method entailing alterations in soil $\mathrm{pH}$. The molecular basis of $\mathrm{Al}$ tolerance should be under more focus, including the novel markers and genes, secondary tolerance indices, BRILs population to develop tolerant varieties in rice but physiological base tolerance mechanisms cannot be overlooked.
\end{abstract}

Keywords: marker-assisted selection, population, preliminary screening, hydroponic solution, genes

\section{Introduction}

Rice is (Oryza sativa L) one of the main staple food of almost of the world population and people are realizing its significance as dietary role. The production of rice needs to enhance on acidic soil where its growth is lower than normal lands (Tao et al., 2018; Nezames et al., 2018). Heavy metals toxicity is a major problem for crop growth globally (Aamer et al., 2018). Al is third most abundant metal in earth crust after oxygen and silicon. Al solubilizes into most phytotoxic forms such as $\mathrm{Alcl}^{3+}$ when soil $\mathrm{pH}$ drops below 5 (Awasthi et al., 2017; Muhammad et al., 2018). About 40-50\% of world arable lands are acidic and leading to Al phyto-toxicity (Von Uexkull and Murter, 1995; Panda et al., 2009). Al is serious growth limiting factor in rice crop grown on acidic soils (Alvim et al., 2012; Pandey et al., 2013). Root growth inhibition is main symptom of Al toxicity and it leads a typical morphological marker to assess the level of Al tolerance in crop (Chandran et al., 2008). This symptom is caused by damaging of root apex by $\mathrm{Al}$ which lead to the decline in grain quality and ultimately affecting the rice production (Li et al., 2013). Root 
growth inhibition, damage of root apex, inhibition of nutrients uptake are the symptoms which appeared within minutes after treated with Al toxicity (Silva et al., 2012). Rice is more tolerant to Al toxicity under hydroponic condition and it is two to five folds more tolerant than other cereals (Maron et al., 2008).

Extent of Al tolerance is affected in many crops such as wheat (Triticum aestivum MILL) (Sasaki et al., 2004), sorghum (Sorghum bicolor) (Magalhaes et al., 2007) and rice (Yamaji et al., 2009). Four mutant's genes lead to Al toxicity have been identified and cloned, such as Nrat1, STAR2, ART1 and STAR1 (Chandran et al., 2008). Al-induced genes STAR1 and STAR2 encode an ATP-binding protein and a transmembrane domain protein, respectively. The STARI-STAR2 complex transports UDP-glucose, a substrate used to modify the cell wall and mask Al-binding sites (Huang et al., 2009). Nratl a (natural resistance-associated macrophage protein) (Nramp) encodes an Al transporter (Xia et al., 2010). It was documented that, Nratl gene induces Al tolerance by transferring $\mathrm{Al}$ into the cell and finally it reduce its concentration in cell wall (Xia et al., 2010). Only Nratl is responsible for natural variation for $\mathrm{Al}$ toxicity tolerance in rice as reported previously (Ma et al., 2002), suggesting that these genes may be accountable for basis of Al toxicity tolerance (Huang et al., 2009; Xia et al., 2010).

QTLs mapping is a powerful tool being used to understand the genetic mechanism of complex traits in crops and it has been used widely to recognize genetic loci determining metals ion uptake and tolerance in rice (Ishikawa et al., 2009; Famoso et al., 2011). A total of 148 QTLs have been reported in rice for Al toxicity tolerance in rice via linkage mapping using bi-parental crosses and genome wide association mapping (Famoso et al., 2011; Zhang et al., 2016). Improving rice tolerance to Al toxicity is primary goal of plant breeders. Screening of the rice varieties with different Al levels would be a better strategy for sustainable agricultural development on acidic soils (Awasthi et al., 2017). Rice crop offers good point for investigating genetic as well as physiological basis of Al tolerance due to its high level of $\mathrm{Al}$ tolerance and genetic resources and $\mathrm{Al}$ tolerance in rice is quantitatively inherited trait (Famoso et al., 2011; Zhang et al., 2016). Rice has been divided into two major groups, japonica (highly resistant to $\mathrm{Al}$ ) and indica (sensitive to $\mathrm{Al}$ toxicity) (Famoso et al., 2011; Zhang et al., 2016) and many QTLs have been reported in rice using different type mapping populations. Acidic soils are worldwide problem and rice production has been decreasing badly due to presence of Al toxicity. Al toxicity tolerance is quantitatively inherited trait and very complex in nature. Genetic mechanism for $\mathrm{Al}$ tolerance is very complex and therefore until now it is not completely unfolded. Lot of studies have been conducted but it's still unclear. Lot of space and scope is present to investigate further to unfold this mechanism. Al tolerance is mainly determined or assessed on the basis of root length trait (Tao et al., 2018). We highlighted novel QTL of latest studies and some earlier studies. We have mentioned some newly reported potent QTL and most of these QTL are novel QTL and on basis of these QTL we made our own prospective that by pyramiding of these QTL via marker-assisted selection, we can enhance $\mathrm{Al}$ tolerance in rice. There is an urgent need to develop rice varieties which can grow best on acidic soils to maintain the production status of rice in order to meet the global food need (Guimaraes et al., 2014). Process of soil acidification is shown in Figure 1. Exact Al tolerance mechanism in rice is not clear. Current review would focus to analyze different tolerance mechanism in rice, especially, quantitative traits loci conferring $\mathrm{Al}$ toxicity tolerance mechanism in rice and to draw a future prospective to develop $\mathrm{Al}$ tolerance varieties to increase rice production on acidic soils. Process of plant growth stimulation and effects of $\mathrm{Al}$ on plant growth are shown in Figure 2. 


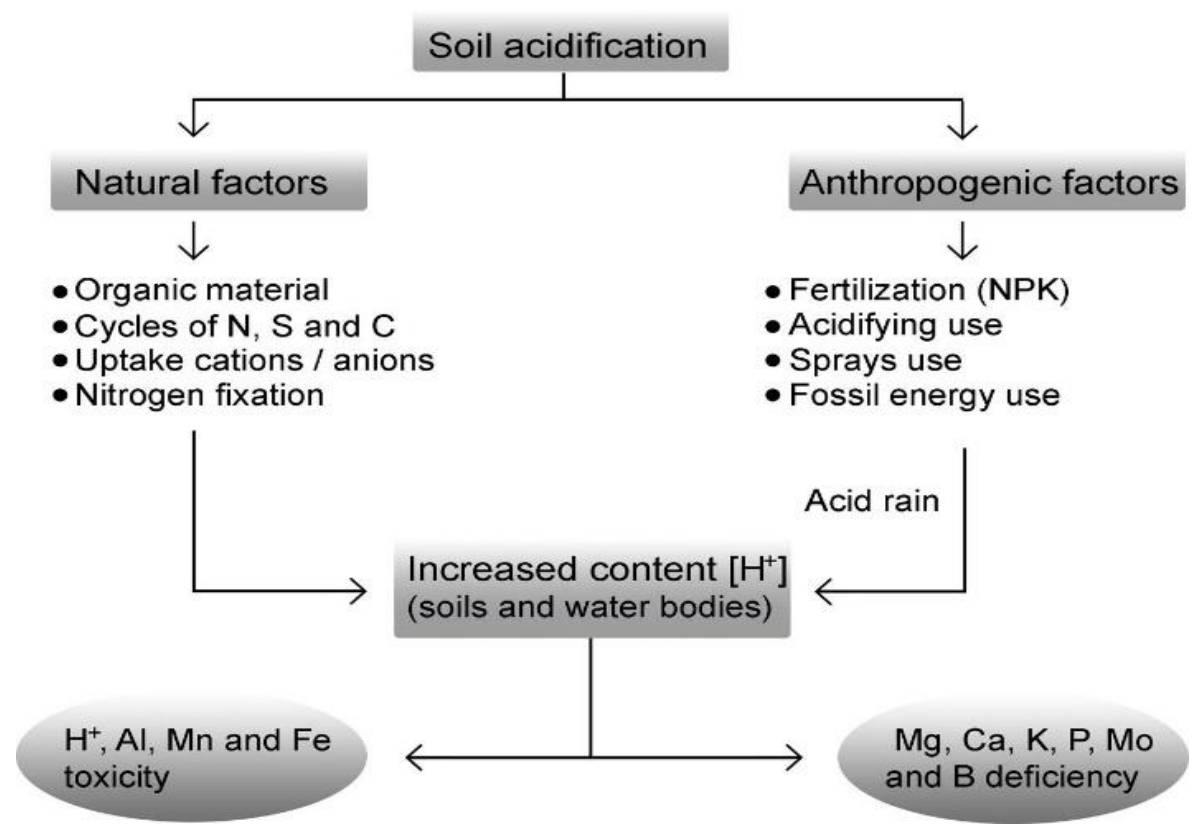

Figure 1. Showed the process of soil acidity with Al. Interaction of Al with other metals in ionic form (adopted from Bojorquez-Quintal et al., 2017)

A

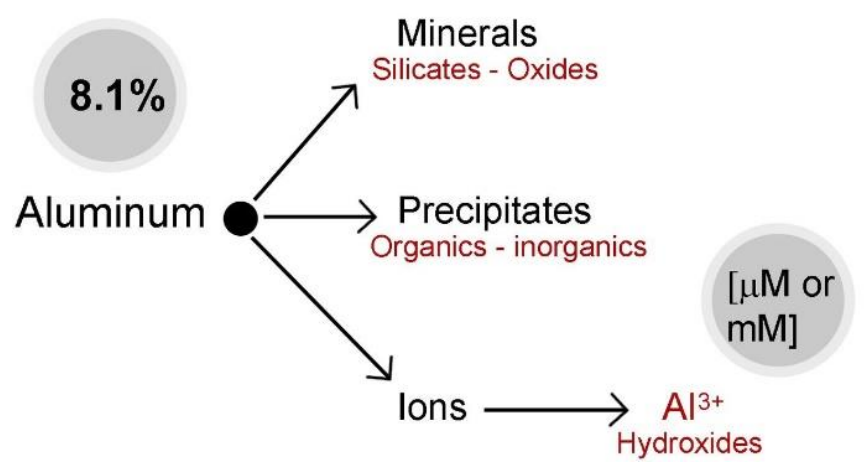

B

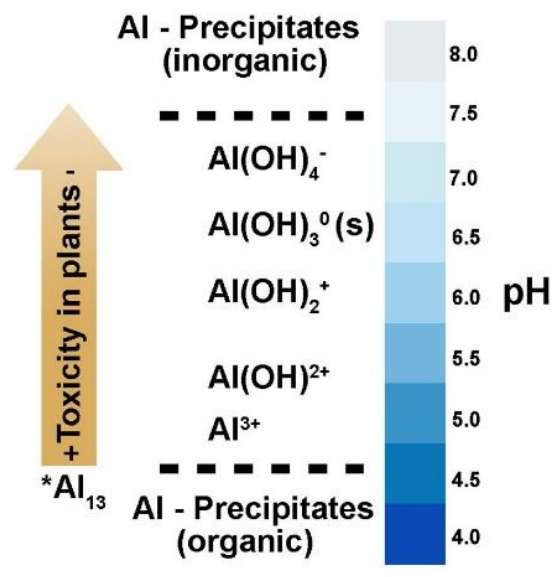

Figure 2. Various type of Al in soil \& water. Al is generally originated in mineral form. Al is either in form of precipitates as well as molecular ions dependent on $\mathrm{pH}$ of the soil. (B) Aluminum types and their effect on plants (adopted from Bojorquez-Quintal et al., 2017)

\section{Effects of Al on rice growth}

\section{Al toxicity}

$\mathrm{Al}$ and other metals are usually present in paddy soils at very low concentration, but excessive use of some fertilizers increases acidity which enhanced concentration of phytotoxic ions (Bidhan and Bhadra, 2014; Awasthi et al., 2017). About 100 years ago, it was first reported that soluble $\mathrm{Al}$ is toxic for crop growth when its concentration rises in acidic soils (Veitch, 1904) and it result in inhibition of root growth (Kopittke et al., 2016). Al becomes more toxic when $\mathrm{pH}$ of the spoils falls below 5 and easily taken by roots therefore inhibiting root growth of rice (Tanaka and Navasero, 1966; Panda et al., 
2009). Rice root growth is restricted by presence of $\mathrm{Al}$ in rhizosphere which significantly reduces crop productivity. In many studies effects of Al toxicity on seedling root growth (RL), shoot length (SL), shoot dry weight (SDW), and root dry weight (RDW) have been investigated. Al toxicity in rice reduces shoot growth by decreasing nutrients $(\mathrm{Ca}, \mathrm{Mg})$ concentration and hormonal imbalance. Roy et al. (2014) also observed significant decrease in shoot length, root length and their dry weight. Al mostly delays and disturbs rice plant metabolism by reducing water absorption (Bidhan and Bhadra, 2014). Process of cell division at root ape is affected by $\mathrm{Al}$ and therefore $\mathrm{Al}$ increases rigidity of the cell wall and reduces the DNA replication (Zhang, 2014; Eekhout et al., 2017). The number of toxic alterations regarding cell division and nucleolus are brought by $\mathrm{Al}$ (Zhang et al., 2014). Al forms an alignment with phosphorous in less existing and insoluble shape in the soils and rice roots, therefore, producing phosphorous deficiency for crop growth.

\section{Positive effects}

Recently, a lot of research articles have been published which deal with role of Al role in economically significant crops, but no evidences have shown its exact role in growth. In case of rice (Famoso et al., 2011; Moreno-Alvarado et al., 2017) observed an increment in rice root growth when exposed to concentration of $\mathrm{Al}(160$ and $200 \mu \mathrm{M})$ toxicity. In rice $\mathrm{Al}$ played a significant role to reduce manganese toxicity which can be related to reduce metals accumulation in shoots which result in decrease Mn contents in shoots. The decrease of manganese application in rice root was a concern of fluctuations in the membrane potential. Al also increased insoluble $\mathrm{Mn}$ contents and altered the functions of junction to cell wall and makes manganese less available to rice roots (Wang et al., 2015, 2017). There are also evidences that Al could significantly increase the contents of chlorophyll, sugar, amino acids and hormones in rice (Mariyama et al., 2016; Xu et al., 2016; Moreno-Alvarado et al., 2017). Al rises the soluble sugar concentration and differentially regulate the expression of NAC transcription factors that can improve rice growth and biomass (Moreno-Alvarado et al., 2017). A view of Al positive effects, its toxic effects and defense mechanism adopted by plants is given below in Figure 3 .

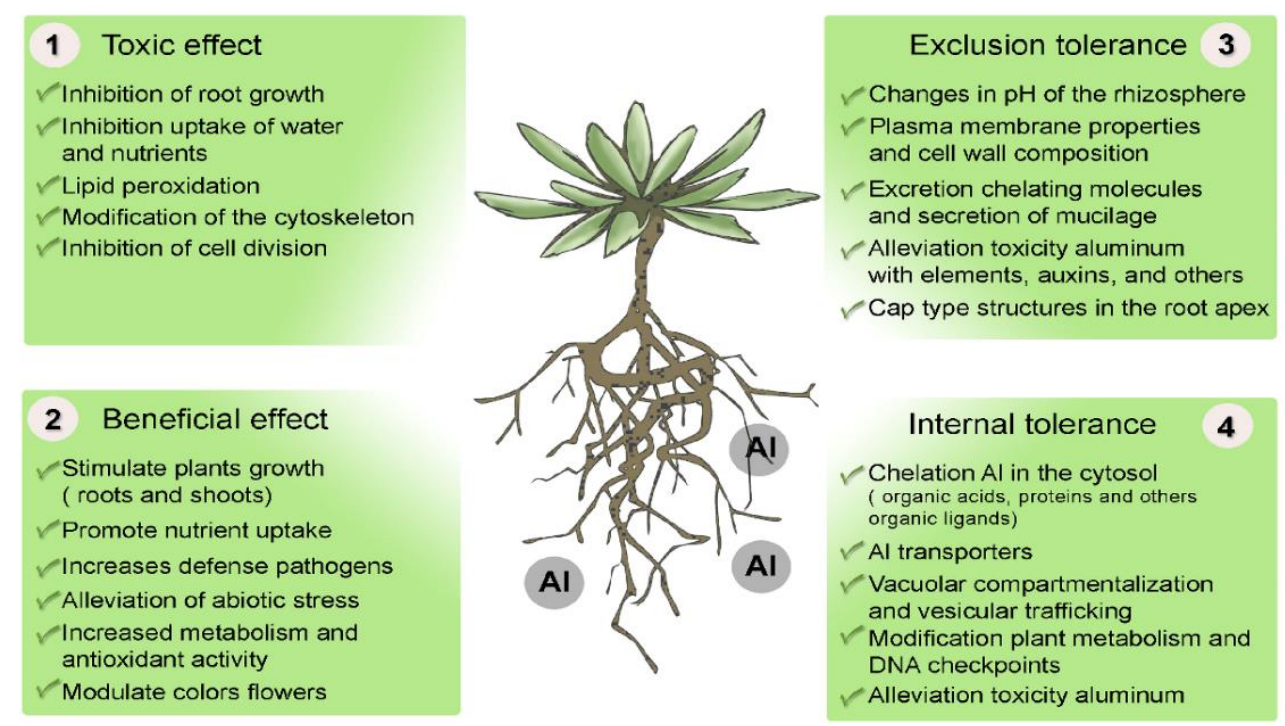

Figure 3. Al toxicity stress, its effects on plants, type of defense mechansim adopted by plants to counter Al stress (adopted from Bojorquez-Quintal et al., 2017) 


\section{Physiological basis of Al tolerance in rice}

A small increase in soil $\mathrm{pH}$ result in reduction in solubility, activity and content of $\mathrm{Al}$ in soil due to secretion of several OA (organic acids) by rice plants roots (Yang et al., 2011). Many evidences regarding biochemical, molecular and physiological mechanism of defense have demonstrated that alterations in cell wall composition may reduce the $\mathrm{Al}$ toxicity in crops (Che et al., 2016; Muhammad et al., 2018). Rice is most tolerant to Al as compared to cereal crops (Yang et al., 2008; Famoso et al., 2010; Escobar-Sepulveda et al., 2017). Yang et al. (2008) observed significant correlation between polysaccharide contents and $\mathrm{Al}$ accumulation in rice and highlighted the significance of cell wall composition. The concentration of pectin and its notch of (methylation) in cell wall added to alterations in tolerance to Al (Eticha et al., 2005; Yang et al., 2011). In rice crop Maejima and Watnanabe (2014) noticed an increment in Al tolerance due to reduction in phospholipids of root cell. For some instance, sterol also played a fruitful role in tolerance to $\mathrm{Al}$ in rice (Hossain et al., 2009; Wagatsuma et al., 2014). Small peptide, attaching the plasma membrane, could stop $\mathrm{Al}$ influx in the cell wall through bonding with cations added confrontation in the rice (Xia et al., 2013). Chelating compounds mucilage in rice has been evidenced to enhance aluminum tolerance. MATE gene (Yang et al., 2011) VUMATE1, has been identified in rice to play key role in mediating citrate efflux in rice, conferring $\mathrm{Al}$ tolerance. Rice adopted several mechanisms to alleviate aluminum toxicity. For example, ammonium decreases the $\mathrm{Al}$ addition of $\mathrm{Al}$ in roots as a result of the $(\mathrm{pH})$ modifications brought through ammonium entrance \& straight cooperation of $\mathrm{Al}$ and ammonium for binding sites of the cell call (Wang et al., 2015).

In rice many genes played a role in internal mechanism of tolerance. OsALS1 is an ortholog of AtALS1 whose expression is brought quickly and specially by aluminum. Inside reclamation of $\mathrm{Al}$ in the rice is brought by OSALS1 is located which is involved in compartmentalization of aluminum in vacuoles (Huang et al., 2009, 2012). In rice several alternative ways of cellular inhalation add to Al tolerance. Lou et al. (2016) advocated that accumulation is responsible in $\left(\mathrm{H}^{+}\right)$and $\mathrm{Al}$ encouraged growth of root in rice. These are all possible physiological ways through which rice can response to Al toxicity to sustain its growth on acidic soils (Eekhout et al., 2017).

\section{Mutant's genes of Al tolerance in rice}

Four mutant genes that responsible for $\mathrm{Al}$ sensitivity in rice have been cloned, Nrat 1 (Nramp aluminum transporter), ART1 (Al rhzotoxcity1, STARl (sensitive to Al rhizotoxcity1) and STAR2 (sensitive to Al rhizotoxcity2) (Huang et al., 2009; Xia et al., 2010) (Table 1). Products of both of genes (STARI and STAR2) are mostly shown in the roots and these are the components of bacterial type genes ABC transporter. These genes are activated after exposure to $\mathrm{Al}$ at transcription level and lose of genes function result in increase in sensitivity to Al toxicity. Arabidopsis sensitive mutants, als1 and als3 also encoding ABC transporters are similar to our genes STAR1 and STAR2 (Larsen et al., 2005, 2007). ART1 gene is a novel (C2H2 type zinc transcription factor) which act together with the starting area of STARI gene. ART1 is reported to involve in regulation of 30 downstream genes which play a strong role in $\mathrm{Al}$ detoxification and increase $\mathrm{Al}$ tolerance in rice crop (Yamaji et al., 2009). The gene (Nrat1) is regulated by ART1 and reported to be involved in $\mathrm{Al}$ transporter that is localized to root cells plasma membrane (Huang et al., 2009; Xia et al., 2010). Nratl gene ensure Al tolerance by transferring Al into cell and decreasing Al concentration in the cell (Xia et al., 2010). Only Nratl genes 
has been studied to have role in natural variations against $\mathrm{Al}$ tolerance, beside this other genes have no role for natural variation of $\mathrm{Al}$ tolerance (Ma et al., 2002) which indicating that these genes might be involved in basis of Al tolerance (Huang et al., 2009; Yamaji et al., 2009; Xia et al., 2010). More accurate and deep investigation is essential to define whether are natural variation linked with these loci which would assist to trace their evolutionary origins which confirmed their role in high level of Al tolerance observed in the rice (Figure 4, Table 1).

Table 1. Al tolerance genes and their function in rice

\begin{tabular}{c|c|c|c|c|c}
\hline Sr No & Crop & Genes & Type & Function & Ref. \\
\hline 1 & Rice & STAR1 & ABC Transporter & Al tolerance & $\begin{array}{c}\text { Larsen et al., } \\
2007\end{array}$ \\
\hline 2 & Rice & STAR2 & ABC Transporter & Al tolerance & $\begin{array}{c}\text { Larsen et al., } \\
2005\end{array}$ \\
\hline 3 & Rice & NRAT1 & Al transporter & Transporting Al into the cell & $\begin{array}{c}\text { Yamaji et al., } \\
2009\end{array}$ \\
\hline 4 & Rice & ART1 & Novel C2H2-type & $\begin{array}{c}\text { Work together with promoter region of } \\
\text { STAR1 }\end{array}$ & $\begin{array}{c}\text { Huang et al., } \\
2009\end{array}$ \\
\hline
\end{tabular}

\section{Candidate Rice Al Tolerance Genes Identified via Forward Genetics Approaches}

\footnotetext{
- Art1: Al regulated transcription factor that activates the expression of candidate tolerance genes.

- STAR1/2: PM ABC transporter that exports UDP-Glucose to the cell wall, possibly reducing $\mathrm{Al}$ binding.

- FRL4: MATE citrate transporter (homolog of SbMATE) that plays a minor role in tolerance.

- Nrat1 \& ALS1: Al transporters that absorb Al from cell wall (Nrat1) and sequester it in vacuole.

- Ma found that none of these genes mapped to previously identified Al tolerance QTL
}

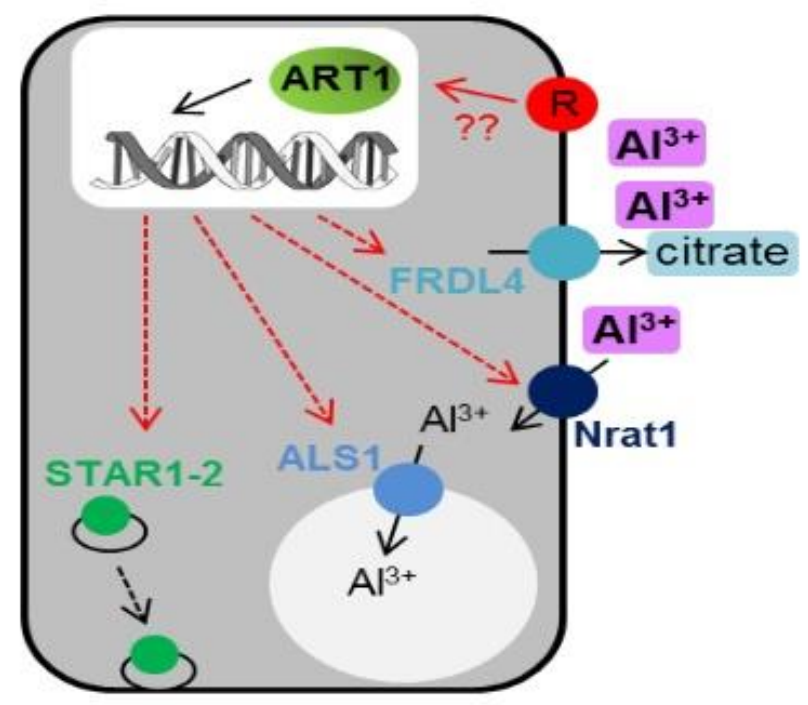

Ma (2007) Syndrome of Al toxicity \& diversity of Al resistance in higher plants. Int. Rev. Cyt. 264:225-253

Figure 4. Showed the candidate Al tolerance genes in rice (adopted from Ma, 2007, Kochian, 2013) 


\section{Putative QTLs expressed after exposure to Al stress}

QTLs mapping is one of the powerful way to mark the specific gene of interest on particular chromosome. Many studies have been conducted in past, identified lot of QTLs for Al tolerance in rice using several mapping several populations. Wu et al. (2000) used hydroponic culture experiment and conducted QTL mapping by using single marker analysis method and identified a QTL $q R R L-12$ for relative root length, explained $12 \%$ and $10 \%$ variation across different populations at second and 4th week of stress which suggested its prolong contribution to Al tolerance in rice. Nguyen et al. (2001) used hydroponic screening technique for Al toxicity tolerance in rice at seedling stage and conducted QTL analysis by method of interval mapping and reported QTL QAlRrla on chromosome 1 which explained $25 \%$ of phenotypic variation and contributed positively towards Al tolerance.

In another study Nguyen et al. (2002) used the hydroponic technique screening technique for $\mathrm{Al}$ toxicity tolerance and detected a significant genomic region $q A L R R-2$ on chromosome 2 by QTL mapping analysis using interval mapping method that contributed greatly to Al tolerance. This QTL indicated that Al tolerance is mainly determined by relative root length ratio of rice seedling evaluated in hydroponic conditions. A genomic region with LOD value of 8.3 with $24.9 \%$ of contribution in variance was involved in natural variation against $\mathrm{Al}$ tolerance and conserved across cereals suggesting the possibilities for QTLs pyramiding to boost Al toxicity tolerance in rice (Ninamango-Cardenas et al., 2003). Nguyen et al. (2003) used nutrient culture solution to sort out the seedling of rice against Al toxicity tolerance and conducted QTL analysis using interval mapping method and detected $Q A l R r 3.1$ which provided important insights into $\mathrm{Al}$ tolerance in rice.

Xue et al. (2006) used hydroponic screening method for Al tolerance using 71 RIL population and conducted QTL analysis using mix linear model method. They identified a novel QTL $q R R E-11$ which provided important case for isolating genes involved in varying mechanism for Al tolerance among cereals. Xue et al. (2007) evaluated rice population in hydroponic solution for screening for Al tolerance and conducted QTLs analysis using composite interval mapping method and identified putative QTLs, $q R R E-1$, $q R R E-11$ which had $17.68 \%$ and $13.53 \%$ of contribution in phenotypic variations and showed positive additive effect, indicated the enhancement of $\mathrm{Al}$ tolerance in rice. A major QTLs AltLRD 9.1 among the flanking markers RM257/RM160 was identified by Famoso et al. (2011) using composite interval method which was responsible for controlling longest root growth in rice RIL population. In this study they grown plants hydroponically for screening for Al tolerance. Soomro and Jian (2015) used two sets of reciprocal introgression lines in hydroponic culture and identified 14 QTLs by QTL analysis across all environments. Some of the QTLs were newly reported QTLs with larger contribution for Al tolerance (Table 2). qAlRL1.1 an Al tolerance QTL was documented by Meng et al. (2017) using GWA analysis conducted by using mix linear model method. Five magic populations were evaluated in hydroponic solution. This region involved in rice tolerance to $\mathrm{Al}$ toxicity and could be exploited to develop $\mathrm{Al}$ tolerant lines in rice. Beside root length, shoot length is also used to determine the degree of $\mathrm{Al}$ tolerance in rice. Recently two QTls $q S L-1$ and $q R L-1$ were identified by Tao et al. (2018) which had 5.7\% and 9.6\% of their contribution in variance. These QTls greatly affected the degree of $\mathrm{Al}$ tolerance in rice seedling. All of these reported regions could be exploited to develop Al tolerant varieties in rice (Table 2). In this study population was 
grown in hydroponic culture solution and GWA analysis was performed using mix linear model approach for mapping of QTLs for Al tolerance.

Table 2. Putative QTLs identified in rice after exposure to Al stress

\begin{tabular}{c|c|c|c|c|c|c|c|c|c}
\hline Parents & Progeny & $\begin{array}{c}\text { Growth } \\
\text { stage }\end{array}$ & Traits & Markers & QTL & Chr & LOD & $\begin{array}{c}\text { PVE } \\
(\%)\end{array}$ & Ref \\
\hline IR1552/Azucena & 150 RIL & Seedling & RRL & $\begin{array}{c}\text { RFLP, } \\
\text { AFLP }\end{array}$ & $q R R L-12$ & 12 & 4.89 & 0.18 & $\begin{array}{c}\text { Wu et al., } \\
2000\end{array}$ \\
\hline $\begin{array}{c}\text { Chiembau/ } \\
\text { Omon269-65 }\end{array}$ & $182 \mathrm{F3}$ & Seedling & RRL & RFLP & QAlRrla & 1 & 10.71 & 25.0 & $\begin{array}{c}\text { Nguyen et } \\
\text { al., 2001 }\end{array}$ \\
\hline $\begin{array}{c}\text { CT9993/ } \\
\text { IR62266 }\end{array}$ & $146 \mathrm{DH}$ & Seedling & RRL & RFLP,SSR & $q A L R R-2$ & 2 & 4.54 & 13.4 & $\begin{array}{c}\text { Nguyen et } \\
\text { al., 2002 }\end{array}$ \\
\hline IR64/ Rufipogon & $171 \mathrm{F6}$ & Seedling & RRL & SSR & QAlRr3.1 & 3 & 8.3 & 24.9 & $\begin{array}{c}\text { Nguyen et } \\
\text { al., 2003 }\end{array}$ \\
\hline Asominori/IR24 & 71 RILs & Seedling & RRE & & QRRE-11 & 11 & 2.64 & 13.53 & $\begin{array}{c}\text { Xue et al., } \\
2006\end{array}$ \\
\hline Asominori/IR24 & 66 CSSLs & Seedling & RRE & RFLP & $q R R E-1$, & 1,11 & 3.60, & 17.68, & $\begin{array}{c}\text { Xue et al., } \\
2007\end{array}$ \\
\hline Azucena/IR64 & $134 \mathrm{RIL}$ & Seedling & LRG & SNP & AltLRD 9.1 & 9 & 6.57 & 0.16 & $\begin{array}{c}\text { Famose et } \\
\text { al., 2011 }\end{array}$ \\
\hline 02428/Munghui & BC2F1 & Seedling & RL & SNP & $q R R L-12$ & 12 & 2.52 & & $\begin{array}{c}\text { Sommro } \\
\text { et al., } \\
2015\end{array}$ \\
\hline $\begin{array}{c}\text { MAGIC } \\
\text { population }\end{array}$ & $=$ & Seedling & RL & SNP & $q A l R L 1.1$ & 1 & & 0.1 & $\begin{array}{c}\text { Meng et } \\
\text { al., 2017 }\end{array}$ \\
\hline & $\begin{array}{c}222,211 \\
\text { Acc }\end{array}$ & Seedling & SL & & $q S L-1$ & 1 & & 5.7 & $\begin{array}{c}\text { Tao et al., } \\
\text { 2018 }\end{array}$ \\
\hline $\begin{array}{c}222,211 \\
\text { Acc }\end{array}$ & Seedling & RL & & $q R L-1$ & 1 & & 9.6 & $\begin{array}{c}\text { Tao et al., } \\
\text { 2018 }\end{array}$ \\
\hline
\end{tabular}

RRL: relative root length, RRE: relative root elongation, LRG: longest root growth, RL: root length, SL: shoot length, QTLs: quantitative trait loci, Acc: Accessions, RIL: recombinant inbred lines, BC: backcross population, DH: double Haploid, CSSL, chromosomal segment substitution lines, Al: aluminum, SNP: single nucleotide polymorphism, SSR: single sequence repeat, AFLP: amplified fragment length polymorphism, RFLP: randomly amplified length polymorphism PVE: phenotypic variance, LOD: lod of algorithm

\section{Genome wide association study (GWAS) and bulk segregant analysis as powerful techniques}

In case of QTLs mapping, it requires development of mapping population and polymorphic markers so it is time consuming and increase labor cost. To overcome this difficulty a new approach is being used by scientists called genome wide association study (GWAS) which is a powerful technique used widely for the QTLs mapping and genes identification. It is widely used for natural resources. GWAS is more accurate in identification of recombination points in genome. By using GWAS we can get large number of significant associations, which lead to fine mapping and gene discovery. GWAS application becomes limited when population size small, therefore for identification of genes, usually requires high SNP density and large population size (Tao et al., 2018). Another most powerful and fast method for identification of QTL is bulk sergeant analysis-seq which includes combination of bulk segregant as well as whole 
genome re-sequencing. Researchers across the world are using these methods nowadays for rapid identification of QTLs and genes for objective trait. Third, use of Model base QTL detection is also an effective and novel way of QTL detection.

\section{QTLs mapping types}

Single marker analysis, interval mapping, composite interval mapping and multi traits mapping. Use of multi traits mapping is one of the best method of QTL analysis in which we can use more than one QTL at same time.

\section{Use of some novel techniques to screen for Al toxicity tolerance in rice}

\section{Use of preliminary screening technique, SSR markers and BRILs population}

One of the best method to determine the $\mathrm{Al}$ tolerance in rice at seedling stage is use of preliminary screening methods. In preliminary experiment rice seedlings can be grown in modified hydroponic culture with different toxic level of Al toxicity. We have used a new modified hydroponic culture to screen for $\mathrm{Al}$ tolerance at seedling stage to build a hypothesis that which dose of $\mathrm{Al}$ toxicity could be best for $\mathrm{Al}$ tolerance. Experiment was comprised of different rice lines which were allowed to grow under various toxic levels $(10,30,50$, and $100 \mathrm{uM})$ of $\mathrm{Al}$. Genotypes showed best response at $100 \mathrm{uM}$ of Al toxicity. By using this method in future studies, possibilities of screening of Al tolerance rice genotypes and identification of QTLs would be more fruitful.

Secondly we used novel rice population in BRILs (backcross recombinant inbred lines) which was developed by our research group (Jiang et al., 2017) at experimental station of Jiangxi Agricultural University, Nanchang, PR. China, in our regular experiment and here we are writing some of its features, which would be ideal population to tolerate $\mathrm{Al}$ toxicity if grown on acidic soils. This population was screened for $\mathrm{Al}$ tolerance at seedling stage and we found a significant difference for Al toxicity tolerance. BRILs population has major portion of genome from its recurrent parent and therefore it's is ideal population for targeted gene cloning. Single sequence repeats are ideal markers which were used for construction of linkage map to find the position of QTLs. Use of other markers do not give ideal information when linkage distance becomes zero, therefore SSR markers would be a best choice for linkage map construction to identify the QTLs for Al toxicity tolerance in rice.

\section{Use of secondary tolerance indices as a new way to determine the Al tolerance}

Al tolerance is mainly based on the relative root length of genotypes, that's why majority of the QTLs reported here are detected for root growth traits. Here we suggest some of the secondly tolerance indices to determine the degree of Al tolerance like, shoot length, shoot fresh weight, root fresh weight, shoot dry weight and root dry weight (Jiang et al., 2017). This index was used in our early study and these morphological attributes could be a potential indicator of $\mathrm{Al}$ toxicity tolerance in rice.

\section{Concluding remarks}

As far as rice growth on acidic soils is concerned, rice breeders have serious concerned to minimize the constraints of $\mathrm{Al}$ toxicity in rice to ensure global food security (Canito et 
al., 2014). Rice production especially in China is greatly influenced by Al toxicity. Many strategies have been presented to enhance rice production on acidic soils. The urgent need is to identify and screen the Al tolerance genotypes in rice using various breeding techniques. Rice has adopted both physiological and molecular mechanism of defense to cope with Al toxicity (Bojorquez-Quintal et al., 2017). Several alterations in soil rhizosphere like $\mathrm{pH}$ changes should be done to minimize the effect of Al toxicity. Soil amendment with various fertilizers can be a viable approach to change the toxic Al into its immobile form so it cannot be entered into roots of rice, acceleration of plant philological defense mechanism, is an important strategy to accelerate the secretion of several organic acids from roots for chelation of $\mathrm{Alcl}^{3+}$ (Kochian et al., 2015). Rice is major Al tolerant crops, but until now no clear mechanism has known which is possibly involve in Al tolerance in rice. Lot of QTLs described above are responsible for governing Al tolerance in rice, which should be isolated and cloned for QTLs pyramiding to develop resistant lines which can grow best on acidic soils.

The various genes such as Nratl which is a novel transporter should be studied more deeply to increase natural variation for Al tolerance. Use of mutation breeding can also be used to generate the mutants in rice population. Different mapping populations such as, BRIL, RIL, IL, CSSL, NIL should be tested against different level of Al tolerance to know their potential against Al. Some novel QTLs like, qRRE-11 and qRRE-1 controlling Al tolerance should be cloned and transferred to develop resistant lines. Real mechanism behind $\mathrm{Al}$ tolerance in rice is still unknown. In end we suggest some novel approaches like, use of preliminary screening technique, use of effective and modified nutrient solution with various levels of Al toxicity, BRIL population, SSR markers, secondary tolerance indices, is best way to select screen Al tolerant lines at seedling stage by applying various levels of Al toxicity, effective QTLs analysis and secondly, use of novel Al phenotyping platform and transcriptional regulation of mutant genes would lead to increase in $\mathrm{Al}$ tolerance in rice. Change in rhizosphere $\mathrm{pH}$ would change the toxic form of $\mathrm{Al}$ into nontoxic form and moreover activation of physiological base defense mechanism can reduce $\mathrm{Al}$ toxicity in rice.

Acknowledgments. Authors are thankful to the Prof Wu Ziming for his financial support during entire study. Authors are also thankful to the lab fellows for their support during manuscript preparation.

Funding. The research was supported by the National Natural Science Foundation of China (31560350 and 31760350), the National Key Research and Development Program of China (2018YFD0301102), the Key Research and Development Program of Jiangxi Province (20171ACF60018 and 20192ACB60003) and the Jiangxi Agriculture Research System (JXARS-18. 


\section{RFERENCES}

[1] Aamer, M., Muhammad, U. H., Abid, A., Su, Q., Liu, Y., Adnan, R., Muhammad, A. U. K., Tahir, A. K., Huang, G. (2018): Foliar application of glycine betaine (GB) alleviates the cadmium $(\mathrm{Cd})$ toxicity in spinach through reducing $\mathrm{Cd}$ uptake and improving the activity of antioxidant systems. - Applied Ecology and Environment Research 16(6): 75757583.

[2] Alia, F. J., Shamshuddin, J., Fauziah, C. I., Husni, M. H. A., Panhwar, Q. A. (2015): Effects of Aluminum, iron and/or low $\mathrm{pH}$ on rice seedlings grown in solution culture. International Journal of Agriculture and Biology 17: 702-710.

[3] Alvim, M., Ramos, F., Oliveira, D., Isaias, R., Franca, M. (2012): Aluminum localization and toxicity symptoms related to root growth inhibition in rice (Oryza sativa L.) seedlings. - Journal of Biosciences 37: 1079-1088.

[4] Arbelaez, J. D., Maron, L. G., Jobe, T. O., Pineros, M. A., Famoso, A. N., Rebelo, A. R., Singh, N., Ma, Q., Fei, Z., Kochian, L. V. (2017): Aluminum resistance transcription factor 1 (ART1) underlies a major $\mathrm{Al}$ resistance QTL and interacts with natural variation in the genetic background to quantitatively regulate $\mathrm{Al}$ resistance in rice. - BioRxiv: 1-17.

[5] Awasthi, J. P., Saha, B., Regon, P., Sahoo, S., Chowra, U., Pradhan, A., Roy, A., Panda, S. K. (2017): Morpho-physiological analysis of tolerance to aluminum toxicity in rice varieties of North East India. - PloS one 12: e0176357.

[6] Bidhan, R., Bhadra, S. (2014): Effects of toxic levels of aluminium on seedling parameters of rice under hydroponic culture. - Rice Science 21: 217-223.

[7] Bojórquez-Quintal, E., Escalante-Magaña, C., Echevarría-Machado, I., Martínez-Estévez, M. (2017): Aluminum, a friend or foe of higher plants in acid soils. - Frontiers in Plant Science 8: 1-16.

[8] Caniato, F. F., Hamblin, M. T., Guimaraes, C. T., Zhang, Z., Schaffert, R. E., Kochian, L. V., Magalhaes, J. V. (2014): Association mapping provides insights into the origin and the fine structure of the sorghum aluminum tolerance locus, AltSB. - PLoS One 9: 1-12.

[9] Chandran, D., Sharopova, N., Ivashuta, S., Gantt, J. S., Van den Bosch, K. A., Samac, D. A. (2008): Transcriptome profiling identified novel genes associated with aluminum toxicity, resistance and tolerance in Medicago truncatula. - Planta 228: 151-166.

[10] Che, J., Yamaji, N., Shen, R. F., Ma, J. F. (2016): An Al-inducible expansin gene, Os EXPA 10 is involved in root cell elongation of rice. - The Plant Journal 88: 132-142.

[11] Eekhout, T., Larsen, P., De Veylder, L. (2017): Modification of DNA Checkpoints to Confer Aluminum Tolerance. - Trends in Plant Science 22: 102-105.

[12] Escobar-Sepúlveda, H. F., Trejo-Téllez, L. I., García-Morales, S., Gómez-Merino, F. C. (2017): Expression patterns and promoter analyses of aluminum-responsive NAC genes suggest a possible growth regulation of rice mediated by aluminum, hormones and NAC transcription factors. - PLoS One 12: 1-25.

[13] Eticha, D., Stass, A., Horst, W. J. (2005): Cell-wall pectin and its degree of methylation in the maize root-apex: significance for genotypic differences in aluminum resistance. - Plant, Cell \& Environment 28: 1410-1420.

[14] Famoso, A. N., Clark, R. T., Shaff, J. E., Craft, E., McCouch, S. R., Kochian, L. V. (2010): Development of a novel aluminum tolerance phenotyping platform used for comparisons of cereal aluminum tolerance and investigations into rice aluminum tolerance mechanisms. - Plant Physiology 153: 1678-1691.

[15] Famoso, A. N., Zhao, K., Clark, R. T., Tung, C.-W., Wright, M. H., Bustamante, C., Kochian, L. V., McCouch, S. R. (2011): Genetic architecture of aluminum tolerance in rice (Oryza sativa) determined through genome-wide association analysis and QTL mapping. PLoS Genetics 7: 1-16.

[16] Guimaraes, C. T., Simoes, C. C., Pastina, M. M., Maron, L. G., Magalhaes, J. V., Vasconcellos, R. C., Guimaraes, L. J., Lana, U. G., Tinoco, C. F., Noda, R. W., JardimBelicuas, S. N., Kochian, L. V., Alves, V. M., Parentoni, S. N. (2014): Genetic dissection 
of Al tolerance QTLs in the maize genome by high density SNP scan. - BMC Genomics 15: 2-14.

[17] Hossain Khan, M. S., Tawaraya, K., Sekimoto, H., Koyama, H., Kobayashi, Y., Murayama, T., Chuba, M., Kambayashi, M., Shiono, Y., Uemura, M. (2009): Relative abundance of $\Delta 5$-sterols in plasma membrane lipids of root-tip cells correlates with aluminum tolerance of rice. - Physiologia Plantarum 135: 73-83.

[18] Huang, C. F., Yamaji, N., Mitani, N., Yano, M., Nagamura, Y., Ma, J. F. (2009): A bacterial-type $\mathrm{ABC}$ transporter is involved in aluminum tolerance in rice. - The Plant Cell 21: 655-667.

[19] Huang, C. F., Yamaji, N., Chen, Z., Ma, J. F. (2012): A tonoplast-localized half-size ABC transporter is required for internal detoxification of aluminum in rice. - The Plant Journal 69: 857-867.

[20] Ishikawa, S., Abe, T., Kuramata, M., Yamaguchi, M., Ando, T., Yamamoto, T., Yano, M. (2009): A major quantitative trait locus for increasing cadmium-specific concentration in rice grain is located on the short arm of chromosome 7. - Journal of experimental botany 61: 923-934.

[21] Jiang, N., Shi, S., Shi, H., Khanzada, H., Wassan, G. M., Zhu, C., Peng, X., Yu, Q., Chen, X., He, X., Fu, J., Hu, L., Xu, J., Ouyang, L., Sun, X., Zhou, D., He, H., Bian, J. (2017): Mapping QTL for seed germinability under low temperature using a new high-density genetic map of rice. - Frontiers in Plant Science 8: 1-9.

[22] Kisnieriené, V., Lapeikaité, I. (2015): When chemistry meets biology: the case of aluminium- a review. - Chemija 26: 148-158.

[23] Kochian, L. V., Pineros, M. A., Liu, J., Magalhaes, J. V. (2015): Plant adaptation to acid aoils: the molecular basis for brop aluminum resistance. - Annual Review of Plant Biology 66: 571-598.

[24] Kochian, L. GCP Project G7009.07: GRM 2013: Cloning, characterization and validation of AltSB/A1 tolerance in rice P1: Leon Kochian, USDA-ARS, Cornel University Co-P1: Susan McCouch, Department of Plant Breeding, Cornel University. - (2013): Technology.

[25] Kopittke, P. M., Menzies, N. W., Wang, P., Blamey, F. P. (2016): Kinetics and nature of aluminium rhizotoxic effects: a review. - Journal of Experimental Botany 67: 4451-4467.

[26] Larsen, P. B., Geisler, M. J., Jones, C. A., Williams, K. M., Cancel, J. D. (2005): ALS3 encodes a phloem-localized $\mathrm{ABC}$ transporter-like protein that is required for aluminum tolerance in Arabidopsis. - The Plant Journal 41: 353-363.

[27] Larsen, P. B., Cancel, J., Rounds, M., Ochoa, V. (2007): Arabidopsis ALS1 encodes a root tip and stele localized half type $\mathrm{ABC}$ transporter required for root growth in an aluminum toxic environment. - Planta 225: 1447-14458.

[28] Li, J. Y., Liu, J., Dong, D., Jia, X., McCouch, S. R., Kochian, L. V. (2014): Natural variation underlies alterations in Nramp aluminum transporter (NRAT1) expression and function that play a key role in rice aluminum tolerance. - Proceedings of the National Academy of Sciences 111: 6503-6508.

[29] Liang, Y. S., Zhan, X. D., Wang, H. M., Gao, Z. Q., Lin, Z. C., Chen, D. B., Shen, X. H., Cao, L. Y., Cheng, S. H. (2013): Locating QTLs controlling several adult root traits in an elite Chinese hybrid rice. - Gene 526: 331-335.

[30] Ma, J. F., Shen, R., Zhao, Z., Wissuwa, M., Takeuchi, Y., Ebitani, T., Yano, M. (2002): Response of rice to $\mathrm{Al}$ stress and identification of quantitative trait loci for $\mathrm{Al}$ tolerance. Plant and Cell Physiology 43: 652-659.

[31] Ma, J. F. (2007): Syndrome of aluminum toxicity and diversity of aluminum resistance in higher plants. - International Review of Cytology 264: 225-252.

[32] Maejima, E., Watanabe, T. (2014): Proportion of phospholipids in the plasma membrane is an important factor in $\mathrm{Al}$ tolerance. - Plant Signaling \& Behavior 9: 29277.

[33] Magalhaes, J. V., Liu, J., Guimaraes, C. T., Lana, U. G., Alves, V. M., Wang, Y. H., Schaffert, R. E., Hoekenga, O. A., Pineros, M. A., Shaff, J. E. (2007): A gene in the 
multidrug and toxic compound extrusion (MATE) family confers aluminum tolerance in sorghum. - Nature Genetics 39: 1156-61.

[34] Maron, L. G., Kirst, M., Mao, C., Milner, M. J., Menossi, M., Kochian, L. V. (2008): Transcriptional profiling of aluminum toxicity and tolerance responses in maize roots. New Phytologist 179: 116-128.

[35] Meng, L., Wang, B., Zhao, X., Ponce, K., Qian, Q., Ye, G. (2017): Association mapping of ferrous, zinc, and aluminum tolerance at the seedling stage in indica rice using MAGIC populations. - Frontiers in Plant Science 8: 1-15.

[36] Moreno-Alvarado, M., García-Morales, S., Trejo-Téllez, L. I., Hidalgo-Contreras, J. V., Gómez-Merino, F. C. (2017): Aluminum enhances growth and sugar concentration, alters macronutrient status and regulates the expression of NAC transcription factors in rice. Frontiers in Plant Science 8: 1-16.

[37] Moriyama, U., Tomioka, R., Kojima, M., Sakakibara, H., Takenaka, C. (2016): Aluminum effect on starch, soluble sugar, and phytohormone in roots of Quercus serrata Thunb. seedlings. - Trees 30: 405-413.

[38] Muhammad, N., Zvobgo, G., Zhang, G. P. (2018): A review: the beneficial effect of aluminum on plant growth in acid soil and the possible mechanisms. - Journal of Integrative Agriculture 17: 60345-7.

[39] Nezames, C. D., Ochoa, V., Larsen, P. B. (2013): Mutational loss of Arabidopsis SLOW WALKER2 results in reduced endogenous spermine concomitant with increased aluminum sensitivity. - Functional Plant Biology 40: 67-78.

[40] Nguyen, V. T., Burow, M. D., Nguyen, H. T., Le, B. T., Le, T. D., Paterson, A. H. (2001): Molecular mapping of genes conferring aluminum tolerance in rice (Oryza sativa L.). Theoretical and Applied Genetics 102: 1002-1010.

[41] Nguyen, V., Nguyen, B., Sarkarung, S., Martinez, C., Paterson, A., Nguyen, H. (2002): Mapping of genes controlling aluminum tolerance in rice: comparison of different genetic backgrounds. - Molecular Genetics and Genomics 267: 772-780.

[42] Nguyen, B. D., Brar, D. S., Bui, B. C., Nguyen, T. V., Pham, L. N., Nguyen, H. T. (2003): Identification and mapping of the QTL for aluminum tolerance introgressed from the new source, Oryza rufipogon Griff., into indica rice (Oryza sativa L.). - Theoretical and Applied Genetics 106: 583-593.

[43] Ninamango-Cárdenas, F. E., Guimarães, C. T., Martins, P. R., Parentoni, S. N., Carneiro, N. P., Lopes, M. A., Moro, J. R., Paiva, E. (2003): Mapping QTLs for aluminum tolerance in maize. - Euphytica 130: 223-232.

[44] Panda, S. K., Baluška, F., Matsumoto, H. (2009): Aluminum stress signaling in plants. Plant Signaling \& Behavior 4: 592-597.

[45] Pandey, P., Srivastava, R. K., Dubey, R. (2013): Salicylic acid alleviates aluminum toxicity in rice seedlings better than magnesium and calcium by reducing aluminum uptake, suppressing oxidative damage and increasing antioxidative defense. - Ecotoxicology 22: 656-670.

[46] Roy, R., Singh, S. K., Chauhan, L., Das, M., Tripathi, A., Dwivedi, P. D. (2014): Zinc oxide nanoparticles induce apoptosis by enhancement of autophagy via PI3K/Akt/mTOR inhibition. - Toxicology Letters 227: 29-40.

[47] Sasaki, T., Yamamoto, Y., Ezaki, B., Katsuhara, M., Ahn, S. J., Ryan, P. R., Delhaize, E., Matsumoto, H. (2004): A wheat gene encoding an aluminum-activated malate transporter. - Plant Journal 37: 645-653.

[48] Silva, S., Pinto, G., Dias, M. C., Correia, C. M., Moutinho-Pereira, J., Pinto-Carnide, O., Santos, C. (2012): Aluminium long-term stress differently affects photosynthesis in rye genotypes. - Plant Physiology and Biochemistry 54: 105-112.

[49] Soomro, A. A., Jian, J. (2015): QTL mapping for Aluminum (Alc13+) toxicity tolerance in two sets of Reciprocal Introgression Lines in Rice (Oryza sativa L.). - International Journal of Scientific \& Engineering Research 6(7): 740-748. 
[50] Tanaka, A., Navasero, S. (1966): Aluminum toxicity of the rice plant under water culture conditions. - Soil Science and Plant Nutrition 12: 9-14.

[51] Tao, Y., Niu, Y., Wang, Y., Chen, T., Naveed, S. A., Zhang, J., Xu, J., Li, Z. (2018): Genome-wide association mapping of aluminum toxicity tolerance and fine mapping of a candidate gene for Nratl in rice. - PLoS One 13: 0198589.

[52] Veitch, F. (1904): Comparison of methods for the estimation of soil acidity. - Journal of the American Chemical Society 26: 637-662.

[53] Von Uexküll, H. R., Mutert, E. (1995): Global extent, development and economic impact of acid soils. - Plant and Soil 171: 1-15.

[54] Wagatsuma, T., Khan, M. S. H., Watanabe, T., Maejima, E., Sekimoto, H., Yokota, T., Nakano, T., Toyomasu, T., Tawaraya, K., Koyama, H. (2014): Higher sterol content regulated by CYP51 with concomitant lower phospholipid content in membranes is a common strategy for aluminium tolerance in several plant species. - Journal of Experimental Botany 66: 907-918.

[55] Wang, L. Q., Yang, L. T., Guo, P., Zhou, X. X., Ye, X., Chen, E. J., Chen, L. S. (2015): Leaf cDNA-AFLP analysis reveals novel mechanisms for boron-induced alleviation of aluminum-toxicity in Citrus grandis seedlings. - Ecotoxicology and Environmental Safety 120: 349-359.

[56] Wang, Y., Li, R., Li, D., Jia, X., Zhou, D., Li, J., Lyi, S. M., Hou, S., Huang, Y., Kochian, L. V. (2017): NIP1; 2 is a plasma membrane-localized transporter mediating aluminum uptake, translocation, and tolerance in Arabidopsis. - Proceedings of the National Academy of Sciences 114: 5047-5052.

[57] Wu, P., Liao, C., Hu, B., Yi, K., Jin, W., Ni, J., He, C. (2000): QTLs and epistasis for aluminum tolerance in rice (Oryza sativa L.) at different seedling stages. - Theoretical and Applied Genetics 100: 1295-1303.

[58] Xia, J., Yamaji, N., Kasai, T., Ma, J. F. (2010): Plasma membrane-localized transporter for aluminum in rice. - Proceedings of National Academy of Science U S A 107: 18381-18385.

[59] Xia, J., Yamaji, N., Ma, J. F. (2013): A plasma membrane-localized small peptide is involved in rice aluminum tolerance. - The Plant Journal 76: 345-355.

[60] Xu, Q., Wang, Y., Ding, Z., Song, L., Li, Y., Ma, D., Wang, Y., Shen, J., Jia, S., Sun, H. (2016): Aluminum induced metabolic responses in two tea cultivars. - Plant Physiology and Biochemistry 101: 162-172.

[61] Xue, Y., Wan, J., Jiang, L., Liu, L., Su, N., Zhai, H., Ma, J. F. (2006): QTL analysis of aluminum resistance in rice (Oryza sativa L.). - Plant and Soil 287: 375-383.

[62] Xue, Y., Jiang, L., Su, N., Wang, J., Deng, P., Ma, J., Zhai, H., Wan, J. (2007): The genetic basic and fine-mapping of a stable quantitative-trait loci for aluminum tolerance in rice. Planta 227: 255-262.

[63] Yamaji, N., Huang, C. F., Nagao, S., Yano, M., Sato, Y., Nagamura, Y., Ma, J. F. (2009): A zinc finger transcription factor ART1 regulates multiple genes implicated in aluminum tolerance in rice. - The Plant Cell 21: 3339-3349.

[64] Yang, J. L., Li, Y. Y., Zhang, Y. J., Zhang, S. S., Wu, Y. R., Wu, P., Zheng, S. J. (2008): Cell wall polysaccharides are specifically involved in the exclusion of aluminum from the rice root apex. - Plant Physiology 146: 602-611.

[65] Yang, Y., Wang, Q., Geng, M., Guo, Z., Zhao, Z. (2011): Rhizosphere pH difference regulated by plasma membrane $\mathrm{H}+$-ATPase is related to differential $\mathrm{Al}$ tolerance of two wheat cultivars. - Plant, Soil and Environment 57: 201-206.

[66] Zhang, H., Jiang, Z., Qin, R., Zhang, H., Zou, J., Jiang, W., Liu, D. (2014): Accumulation and cellular toxicity of aluminum in seedling of Pinus massoniana. - BMC Plant Biology 14: 264.

[67] Zhang, P., Zhong, K., Tong, H., Shahid, M. Q., Li, J. (2016): Association mapping for aluminum tolerance in a core collection of rice landraces. - Frontiers in Plant Science 7: 211 . 